\title{
Evaluation of Aspirin effect on Candida Glabrata isolates with resistance to azole compounds by real- time PCR
}

\author{
Abstract \\ Background and objective:Among the Candida species, Candida glabrata (C. glabrata) \\ is inherently resistant to anti-mycotic agent, azole. The aim of this study was to assess \\ the effects of Aspirin as an anti-inflammatory drug on azole-resistant Candida glabrata \\ in- vitro.
}

Materials and methods:Five C. glabrata isolates were collected from patients with candidal vulvovaginitis referred to clinic. The antibiotic susceptibility test of isolates for fluconazole was performed according to the CLSI M38-A2 standard protocol. A $64 \mu \mathrm{g} / \mathrm{ml}$ aspirin and $500 \mathrm{ug} / \mathrm{ml}$ and likewise $64 \mu \mathrm{g} / \mathrm{ml}$ fluconazole were used for the MIC detection test. The RNA of isolates was prepared according to the manufacturer's instruction. Synthesis of cDNA was conducted with the $1621 \mathrm{~K}$ kit (Fermentase).. The RT-PCR reaction was set up for ERG3, ERG6 and ERG11 genes and the housekeeping gene Beta-actin $(\beta$-actin) was amplified as internal control.

Results:All of the isolates were resistant to fluconazole and aspirin. In the concentration of the aspirin at the $500 \mathrm{ug} / \mathrm{ml}$ and the MIC and MBC were $15.62 \mu \mathrm{g} / \mathrm{ml}$ and $31.25 \mu \mathrm{g}$ / $\mathrm{ml}$, respectively. In the RT-PCR reaction, the erg6 was expressed at the concentration of $15.62 \mu \mathrm{g} / \mathrm{ml}$, but no expression was detected without the aspirin exposure. However, the expression profile of erg3 and erg 11 was not detected. However, aspirin conferred a fatal effect at the concentration of $31.25 \mu \mathrm{g} / \mathrm{ml}$, as no growth of the strains was observed.

Conclusion:The present study exhibited that aspirin induce the anti-fungal effect of fluconazole at high concentrations conferring a synergistic effect and fungicidal activity.
Volume 5 Issue $6-2017$

\author{
Zohreh Zamanian,' Farshad Nojoomi, ${ }^{2}$ \\ Mahtab Vafaei, ${ }^{3}$ Fahimeh Bagheri ${ }^{4}$ \\ 'Department of Microbiology, Faculty of Medicine, AJA \\ University of Medical Sciences, Iran \\ 2Department of Microbiology, Tehran Medical Sciences Branch, \\ Islamic Azad University, Iran \\ Biotechnology research center, Islamic Azad University, Iran \\ ${ }^{4}$ Department of Microbiology, Islamic Azad University, Kazeroon \\ Branch, Iran
}

Correspondence: Zohreh Zamanian, Department of Microbiology, Islamic Azad University, Kazeroon Branch, Iran, Tel 218|224563,Email bacteriology94@gmail.com

Received: January 01, 2017 | Published: July 06, 2017

Keywords:Candida glabrata, Aspirin, Azole-resistance, In vitro

\section{Introduction}

Candida glabrata that was previously viewed as a nonpathogenic commensal microorganism of human mucosal tissues, is the second or third nosocomial Candida $s p$ and related infections (mucosa and systemic) have significantly increased due to the use of immunosuppressive agents. ${ }^{1}$ Among the Candida species, C. glabrata is inherently resistant to azole anti mycotic agents. A common mechanism for resistance is reduction of antifungal drug via over expression of efflux pumps (Cdr1, Cdr2 and Mdr1). ${ }^{2-4} \mathrm{Cdr} 1$ and $\mathrm{Cdr} 2$ are belonged to the $\mathrm{ABC}$ family and ATP dependent trans- membrane proteins. Several previous studies have exhibited those modulators such as ibuprofen; FK506 (tacrolimus) and calcineurin inhibitor can revert resistance or suppress the development of resistance of Candida spp. ${ }^{5,6}$ The mutations occurred in several ergo sterol biosynthesis genes including ERG1,ERG3, ERG6,ERG7,ERG9 and $E R G 11$ confer the resistance to azoles. ${ }^{7}$ The nonessential gene $E R G 6$ encoding an $S$-adenosylmethionine: 24 methyltransferase, undergoes mutations which can develop multiple phenotypes, including, decreased ergo sterol content, increased resistance to polyenes and increased cyclohexamide sensitivity. ${ }^{8}$ The accumulation of $E R G 3$ gene products including 14 -methylated sterols and 14_-methylergosta-8, 24(28)-dien-3, 6-diol play an important role in azole sensitivity, thus inactivation of the gene or mutations can confer the resistance, because of lack of enzymatic degradation. In C. glabrata mutation in $E R G 3$ does not always caused resistance to azole compounds. ${ }^{9}$ Occurrence of point mutations in the ERG11 gene encoding lanosterol 14a-demethylase is another mechanism of resistance. ${ }^{10}$ The erg11 positive selection was done on a polyene-containing medium and under aerobic conditions. ${ }^{9}$ the expression of ERG11 decreases in the stationary phase of growth of C.albicans and causes resistance of biofilms to azole drugs. ${ }^{11}$ The non-streoidal anti-inflammatory drugs (NAID) especially Ibuprofen Diclofenac and Aspirin have been shown to have inhibitory effect on biofilm formation and decrease of drug resistance. ${ }^{12}$ Several studies on the other hand, have shown that aspirin can effect on Staphylococcus epidermidis biofilms. ${ }^{13}$ The aim of this study was to assess the effects of Aspirin as an antiinflammatory drug on azole-resistant $C$. glabrata invitro.

\section{Materials and methods}

\section{Fungal isolates}

Five standard C. glabrata isolates 625, 10116, 8933, 194, 634 and 2010 were separated from patients with candidal vulvovaginitis referred to the female clinic of Dr. Shariati hospital of Tehran. The $C$. glabrata cultures were identified with conventional tests.

\section{The minimum inhibitory concentration (MIC) test}

The antibiotic susceptibility test of $C$. glabrata isolates for fluconazole and aspirin was performed according to the CLSI M38-A2 standard protocol. ${ }^{14}$ A suspension of $5 \times 104$ concentration of each isolate was prepared. The serial dilution for MIC was done by mixing RPMI 1640 medium and drugs in sterile saline $($ each $=100 \mu 1)$ into 96 well plates and inoculated. The RPMI with and without suspension were used as the control positive and negative, respectively. The plates were incubated in $35^{\circ} \mathrm{C}$ for $72 \mathrm{~h}$ and the $\mathrm{pH}$ was equal to 7 (repeated 5 times). For the confirmation of growth of isolates, $10 \mu 1$ of each well component was inoculated to the sabouraud dextrose agar plates. The 
MIC and minimum fungicidal concentration (MFC) were measured considering the growth on SabDex agar and counting of colonies.

\section{Aspirin effect on resistant isolates}

Concentrations of $64 \mu \mathrm{g} / \mathrm{ml}$ and $128 \mu \mathrm{g} / \mathrm{ml}$ aspirin were used for the MIC detection test. Each stock was used into two different concentrations of CLSI protocol and without dilution. The alcohol and DMSO were separately used for dilution of aspirin. Next, the isolates suspension concentration was diluted $1 / 10$. The effect of sub-inhibitory amount of 200ul volume of aspirin (64 and 128 and $256 \mu \mathrm{g} / \mathrm{ml}$ ) in forms of CLSI protocol and without dilution) and also fluconazole in volume and concentration equal to that of aspirin were measured. Moreover, in higher concentration of aspirin $(500 \mu \mathrm{g} / \mathrm{ml})$, the MIC and MBC of aspirin was detected. In each micro-plate, 100ul of each of drug, and RPMI was inoculated.

\section{RNA Extraction}

The RNA of isolates was prepared with Gene JET kit (Fermentas) according to the manufacturer's instruction. Briefly, two solutions of $2 \mathrm{ME}+$ lysis buffer $(20 \mu \mathrm{l}+980 \mu \mathrm{l}$ for each isolate) and proteinase $\mathrm{K}$ + TE buffer $(10 \mu 1+590 \mu l)$ were prepared. RNA was extracted from isolates that have grown in last dilution of wells. For each test $6 \times 10^{8}$ cells was used. Isolated RNA was preserved in $-20^{\circ} \mathrm{C}$.

\section{cDNA Synthesis}

Synthesis of cDNA was conducted with the $1621 \mathrm{~K}$ kit (Fermentase) and according to manufacturer's instruction. Briefly, $2 \mu \mathrm{g}$ of RNA was added to $1 \mu 1$ of Random hexamer primer and the final volume was reached to $12 \mu 1$ using DEPC treated water. The microtubes were placed in $65^{\circ} \mathrm{C}$ for $5 \mathrm{~min}$ and next on ice. For each tube, $4 \mu 1$ of $10 \mathrm{X}$ buffer, $2 \mu 1$ of dNTP $(10 \mathrm{mmol}), 1 \mu 1$ ribonuclease and $1 \mu 1$ of Reverse Transcriptase M-MuL were added. The thermal profile of reaction included of $25^{\circ} \mathrm{C}(5 \mathrm{~min}), 42^{\circ} \mathrm{C}(60 \mathrm{~min}), 70^{\circ} \mathrm{C}(10 \mathrm{~min}$ for the reaction stop). The cDNA was preserved in $-20^{\circ} \mathrm{C}$ until used in PCR reaction.

\section{Real Time PCR Test}

The RT-PCR reaction was set up for ERG3, ERG6 and ERG11 genes (Tables1 \& 2). Primer designing for RT-PCR test was performed using GenBank (the international bank in NCBI). Master Mix was prepared the same for each reaction (erg3, erg6, erg11 and $\beta$-actin) as shown in Table. The thermal reaction profile included of $95^{\circ} \mathrm{C}(5 \mathrm{~min})$, $95^{\circ} \mathrm{C}(50 \mathrm{~s}), 60^{\circ} \mathrm{C}(45 \mathrm{~s}), 72^{\circ} \mathrm{C}(50 \mathrm{~s})$ and final extension of $72^{\circ} \mathrm{C}$ (10min). The agarose gel of $1.8 \%$ and ethidium bromide were used for the visualization of products.

Table I The master mix prepared for PCR reactions (erg3, erg6, erg II and $\beta$-actin)

\begin{tabular}{ll}
\hline Master Mix & Total=20ul \\
\hline Syber Green & IOul \\
Primer sense & $0.8 \mathrm{ul}$ \\
Primer Antisense & $0.8 \mathrm{ul}$ \\
cDNA & $2 \mathrm{ul}$ \\
$\mathrm{H}_{2} \mathrm{O}$ & $6.4 \mathrm{ul}$ \\
\hline
\end{tabular}

Table 2 The sequence and conditions of primers used in this study

\begin{tabular}{llllll}
\hline Name & nt & OD & GC\% & Tm & Primers sequences (5' to 3') \\
\hline ERG3-S & 20 & 12 & 50 & 58.65 & AGTGGGTGCAGTGATACAGT \\
ERG3-AS & 20 & 12 & 50 & 59.22 & TGCGGGTAAGAAGGTTGGTT \\
ERG6-S & 20 & 12 & 55 & 59.82 & AGCTACCGTTCATGCTCCAG \\
ERG6-AS & 20 & 12 & 55 & 59.75 & GTTCGGCAACTTCACGACTG \\
ERGII-S & 20 & 12 & 45 & 59.88 & CAGAAAAGTGGCGTTGTTGA \\
ERGII-AS20 & 12 & 45 & 59.69 & GCAGCATCACGTTTCCAATA \\
\hline
\end{tabular}

\section{Results}

\section{MIC tests for fluconazole and aspirin}

All the isolates were resistant to fluconazole and $64 \mu \mathrm{g} / \mathrm{ml}$ aspirin serial mico-dilutions. The concentration of the aspirin at the next stage was increased to $500 \mathrm{ug} / \mathrm{ml}$ and the next MIC and MBC were $15.62 \mu \mathrm{g} /$ $\mathrm{ml}$ and $31.25 \mu \mathrm{g} / \mathrm{ml}$, respectively by culture of $100 \mathrm{ul}$ isolates from suspension on the agar plate.

\section{The RT-PCR reaction for Erg3, Erg6 and Erg I / Genes}

In the RT-PCR reaction, the erg6 was expressed (CT cycle of 22 ) with the housekeeping gene of $\beta$-actin which was amplified at the cycle of 22 , and the expression was significantly increased when using aspirin at the concentration $15.62 \mu \mathrm{g} / \mathrm{ml}$ for the growth inhibition of C. glabrata. However, the expression profile of erg3 and erg 11 was not detected before the cycle of 38 , and thus no effect was induced by aspirin on the both genes. The amplification of erg6 was detected at $15.62 \mu \mathrm{g} / \mathrm{ml}$ and C. glabrata were capable of growth at this concentration $(\mathrm{MIC}=15.62)$. However, aspirin conferred a fatal effect at the concentration of $31.25 \mu \mathrm{g} / \mathrm{ml}$, as no growth of the strains was observed.

\section{Discussion}

C. glabrata belongs to the normal microbiota of the oral cavity to gastrointestinal and vaginal tracts, and related clinical manifestations are more recurrent and problematic to treat mainly due to decreased azole susceptibility; and especially when any level of immunosuppressive agents are given to patients. ${ }^{7}$ Aspirin as an NSAID drug was adopted for this study because before surveys have shown evidence of effect of these drugs on the expression of erg genes. ${ }^{15,16}$ The erg genes are responsible for the azole resistance and thus the three erg3, erg6 and $\operatorname{erg} 11$ were assessed here in order to combat drug resistance due to C. glabrata isolates. In the present study, MIC for fluconazole and aspirin was conducted and all the isolates were resistant to the $46 \mu \mathrm{g} / \mathrm{ml}$ of these drugs. But at concentrations of $500 \mathrm{ug} / \mathrm{ml}$, the MIC and MFC were 15.62 and $31.25 \mu \mathrm{g} / \mathrm{ml}$, respectively. Non-steroidal anti-inflammatory drugs according to previous studies have anti-fungal activity. In a survey by Sharma, All the isolates of C. albicans and nearly all of C. parapsilosis, $37.7 \%$ of $C$. tropicalis isolates exhibited significant reduction in MIC after concomitant culture with fluconazole and ibuprofen and no inhibition of growth was demonstrated among any isolate of C. glabrata $^{17}$ Testing of Diclofenac sodium, Ibuprofen and Ketoprofen, by Ashraf et al., Sodium Diclofenac showed lower MIC against $C$. albicans and $C$. glabrata, while ibuprofen demonstrated lower MIC against $C$. krusei compared to other NSAIDs. On the other hand, these drugs showed antifungal and antiadherent activities, and were capable of detaching mature biofilms. Also, morphological switch of C. albicans was inhibited at a concentration of $500 \mu \mathrm{g} / \mathrm{ml}$ Sodium Diclofenac. ${ }^{18}$

In the RT-PCR test, the erg6 gene was amplified before the cycle of 38, but erg3 and erg 11 were not amplified compared to the control $\beta$-actin gene. However, the expression profile of erg3 and $\operatorname{erg} 11$ was not detected before the cycle of 38. The amplification of erg6 was detected at $15.62 \mathrm{ug} / \mathrm{ml}$ Aspirin and C. glabrata were capable of growth at this concentration $(\mathrm{MIC}=15.62)$. However, aspirin conferred a fatal effect at the concentration of $31.25 \mathrm{ug} / \mathrm{ml}$, as no expression of erg6 was detected and also no growth of the strains was observed. Different azole resistant genes and several homologues have been recognized to date. ${ }^{19}$ Sequencing of CgERG4, CgERG11, CgERG5 and CgERG6 genes by Vandeputt determined exclusively a single missense mutation in the CgERG6 culminating in the substitution of cysteine 
by phenylalanine aminoacide. ${ }^{20}$ Moreover, a nonsense mutation in this gene has led to reduced susceptibility to azole compounds. ${ }^{21}$ There may be a relationship between the mutations and the overexpression of erg6 we revealed. However, in the study by Tobudic alterations in the $E R G 11$ gene was considered as an important way of azole resistance. ${ }^{22}$ The present study exhibited that aspirin induce the antifungal effect of fluconazole at higher concentrations conferring a synergistic effect; especially via alteration of erg6 expression and leading to the $C$. glabrata strains susceptible to azole compound. However, we observed that aspirin has no effect on the expression of erg3 and ergll genes. This was the first report of aspirin effect on the expression of erg genes.

\section{Acknowledgments}

This study was supported by AJA and Kazeroon Islamic Azad University.

\section{Conflict of interest}

None.

\section{References}

1. Fidel PL, Vazquez JA, Sobel JD. Candida glabrata:review of epidemiology, pathogenesis, and clinical disease with comparison to C. albicans. Clin Microbiol Rev. 1999;12(1):80-96.

2. Prasad R, De Wergifosse P, Goffeau A, et al. Molecular cloning and characterization of a novel gene of Candida albicans, CDR1, conferring multiple resistance to drugs and antifungals. Curr Genet. 1995;27(4):320-329.

3. Sanglard D, Ischer F, Monod M, et al. Cloning of Candida albicans genes conferring resistance to azole antifungal agents:characterization of CDR2, a new multidrug $\mathrm{ABC}$ transporter gene. Microbiology. 1997;143(2):405-416.

4. Fling ME, Kopf J, Tamarkin A, et al. Analysis of a Candida albicans gene that encodes a novel mechanism for resistance to benomyl and methotrexate. Mol Gen Genet. 1991;227(2):318-329.

5. Marchetti O, Moreillon P, Glauser MP, et al. Potent synergism of the combination of fluconazole and cyclosporine in Candida albicans. Antimicrob Agents Chemother. 2000;44(9):2373-2381.

6. Pina-Vaz C, Rodrigues AG, Costa-de-Oliveira S, et al. Potent synergic effect between ibuprofen and azoles on Candida resulting from blockade of efflux pumps as determined by $\mathrm{FUN}-1$ staining and flow cytometry. Journal of Antimicrobial Chemotherapy. 2005;56(4):678-685.

7. Rodrigues CF, Silva S, Henriques M. Candida glabrata:a review of its features and resistance. Eur J Clin Microbiol Infect Dis. 2014;33(5):673-688.

8. Young LY, Hull CM, Heitman J. Disruption of ergosterol biosynthesis confers resistance to amphotericin B in Candida lusitaniae. Antimicrob Agents Chemother. 2003;47(9):2717-2724.
9. Sanglard D, Ischer F, Parkinson T, et al. Candida albicans mutations in the ergosterol biosynthetic pathway and resistance to several antifungal agents. Antimicrob Agents Chemother. 2003;47(8):2404-2412.

10. Marichal P, Koymans L, Willemsens S, et al. Contribution of mutations in the cytochrome P450 14 $\alpha$-demethylase (Erg11p, Cyp51p) to azole resistance in Candida albicans. Microbiology. 1999;145(10):2701-2713.

11. Yu L-h, Wei X, Ma M, et al. Possible inhibitory molecular mechanism of farnesol on the development of fluconazole resistance in Candida albicans biofilm. Antimicrob Agents Chemother. 2012;56(2):770-775.

12. Alem MA, Douglas LJ. Effects of aspirin and other nonsteroidal anti-inflammatory drugs on biofilms and planktonic cells of Candida albicans. Antimicrob Agents Chemother. 48(1):41-47.

13. Farber BF, Wolff AG. The use of nonsteroidal antiinflammatory drugs to prevent adherence of Staphylococcus epidermidis to medical polymers. J Infect Dis. 1992;166(4):861-865.

14. Pfaller M, Boyken L, Hollis R, et al. In vitro susceptibility of clinical isolates of Aspergillus spp. to anidulafungin, caspofungin, and micafungin:a head-to-head comparison using the CLSI M38-A2 broth microdilution method. J Clin Microbiol. 2009;47(10):3323-3325.

15. Szabo IL, Pai R, Soreghan B, et al. NSAIDs inhibit the activation of egr-1 gene in microvascular endothelial cells. A key to inhibition of angiogenesis? J Physiol Paris. 2001;95(1):379-383.

16. Petrovic I, Nikcevic G, Zaric J, et al. VEGF and TNF up-regulate, NSAID down-regulate SOX18 protein level in HUVEC. Open Life Sciences. 2010;5(4):427-434.

17. Sharma M, Biswas D, Kotwal A, et al. Ibuprofen-Mediated Reversal of Fluconazole Resistance in Clinical Isolates of Candida. Journal of clinical and diagnostic research:J Clin Diagn Res. 2015;9(1):DC20DC22.

18. Ashraf A, Yousri F, Taha N, et al. Effect of Some Non steroidal AntiInflammatory Drugs on Growth, Adherence and Mature Biofilms of Candida spp. American Journal of Microbiological Research. 2015;3(1):1-7.

19. Whaley SG, Caudle KE, Vermitsky J-P, et al. UPC2A is required for high-level azole antifungal resistance in Candida glabrata. Antimicrob Agents Chemother. 2014;58(8):4543-4554.

20. Vandeputte $P$, Tronchin $G$, Bergès $T$, et al. Reduced susceptibility to polyenes associated with a missense mutation in the ERG6 gene in a clinical isolate of Candida glabrata with pseudohyphal growth. Antimicrob Agents Chemother. 2007;51(3):982-990.

21. Vandeputte P, Tronchin G, Larcher G, et al. A nonsense mutation in the ERG6 gene leads to reduced susceptibility to polyenes in a clinical isolate of Candida glabrata. Antimicrob Agents Chemother. 2008;52(10):3701-3709.

22. Tobudic S, Kratzer C, Presterl E. Azole-resistant Candida spp.-emerging pathogens? Mycoses. 55(s1):24-32. 